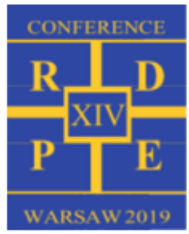

\title{
Oily water emulsification as the method of its pre-treatment for utilization via co-combustion
}

\author{
A leksandra Dzido ${ }^{1,}{ }^{*}$, Piotr K rawczyk ${ }^{1}$, M ichalina K urkus-Gruszecka ${ }^{1}$ and K rzysztof B adyda ${ }^{1}$ \\ 1 Institute of Heat Engineering, W arsaw University of Technology, N owowiejska 21/25, 00-665 W arsaw, \\ aleksandra.dzido.dokt@pw.edu.pl, Poland
}

\begin{abstract}
Oily water can be the side product of many processes, like crude oil processing and transportation leakages, industries such as steel industry, machine industry, petroleum refinery, petrochemical industry, textile industry, metal industry, pyrolysis etc. It seems to be the difficult to dispose waste. Although several treatment methods have been developed, many times additional water disposal installation is required. When the main process consumes natural gas, to simplify oily water utilization, the method of its direct injection to the natural gas burner is suggested by the paper authors. To provide the proper combustion and the mixture homogenization, emulsification was proposed. The aim of the research was to find the optimal recipe from the stability point of view, taking into account technical and economic conditions. The article covers the variety of surfactants examination for the water-hydrocarbons mixture emulsification, including the surfactants concentration optimization.
\end{abstract}

\section{Oily water disposal}

Oily water seems to be the larger waste product of oil and gas production, although the others sectors as steel industry, machine industry, textile industry, metal industry, pyrolysis also contribute to this kind of waste world production. Nowadays challenge is to propose economic viable way of the oily water purification, as it can go back to the natural environment without any damage for the biotope and inanimate nature. The cleanup process focuses mainly on the oil and water separation. Significant amount of researchers have reported interesting results in this field [1], [2], [3], [4], [5], [6], [7]. A mong the most common purification methods the following can be enumerated [8], [9]:

Flotation - it is the process in which the tiny air bubbles are introduced to the polluted water. Due to the fact that the floating density of oil is less than that of water, oil droplets via adhesion go up with the bubbles. Finally the scum layer has to be separated from water fraction.

Coagulation - the process in which the emulsified or dissolved oil, with the presence of coagulant - typically metallic salts, forms a greater structure characterized by the irregular shape. In this form it is significantly easier to remove the oil from water.

Biological treatment - the process bases on the contaminant consumption by the microorganisms. The phenomena occur usually in the sludge, which consist of biological matter. In the following step, water is separated from the sludge.

Membrane separation technology - bases generally on the pressure driven processes with the help of the porous membrane. Membrane separation is a kind of physical removal, among the others: microfiltration, ultrafiltration, nanofiltration and reverse osmosis can be enumerated.

As justified above the oily water is a difficult dispose waste, but several purification technologies were developed. The authors of this paper propose another method of its utilization. It can be noticed that the oily water many times is generated in the industry in which the natural gas or petrol is used. In the paper the idea of the oily water emulsification and co-combustion with the natural gas is presented as the way of its utilization.

\section{Emulsions}

\subsection{Emulsions types}

An emulsion by the definition is a mixture of two or more liquids that are normally immiscible and can be classified as a kind of colloid, where both phases are liquid. Emulsions can be also classified as thermodynamically unstable multiphase systems [10], that is why to increase its stability some chemicals called surfactants (discussed deeply in the further part of the article) can be added. Typical dispersed liquid droplets size for emulsions can take values from 0.001 to $0.05 \mathrm{~mm}$. Various types of emulsions can be enumerated: water in oil $(\mathrm{w} / \mathrm{o})$, oil in water $(\mathrm{o} / \mathrm{w})$ and multiple emulsions [11] as shown in the fig. 1. Emulsion does not have to consist of only two liquids. Multicomponent double emulsions are described in [12] [13]. A nother emulsion type are emulsions with extremely high internal volume fraction [14]. Their internal structure takes the shape of hexagons, which enable to obtain inner phase concentration greater than $99 \%$. 

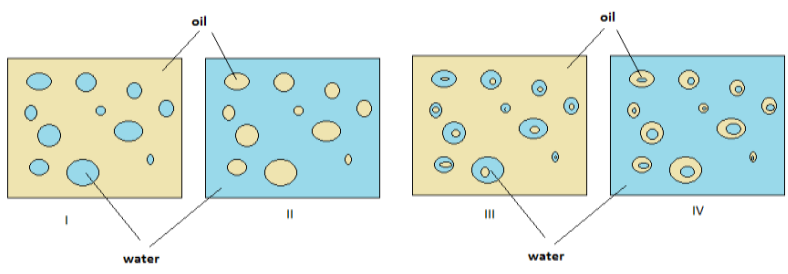

Fig. 1. Emulsions types: I- water in oil, II - oil in water, III multiple emulsion w/o/w, IV - multiple emulsion o/w/0.

\subsection{Emulsions generation methods}

\subsubsection{Mechanical [15]}

One of the most common emulsification techniques is mechanical mixing. The rotation of the stirrer causes turbulences, which lead to the fluid elements motion, and finally to the phase mixing resulting in the breakage of droplets and the emulsion formation. The process of emulsification with a mechanical agitator consists of two stages: initial emulsification and proper emulsification. In the first stage, water, organic phase and emulsifier (surfactant) are mixed. The emulsifier can be added first to only one phase or to both phases simultaneously. As a result of the initial emulsification, a primary emulsion is formed, from which the specific emulsion is obtained in the second stage. The second emulsification stage involves the deformation of large droplets and their decay.

\subsubsection{High pressure homogenization [16], [17]}

High pressure homogenizers pumps the liquid, through a narrow gap formed by stationary parts. The high flow velocity, which in the cross-section of the gap can reach up to $200 \mathrm{~m} / \mathrm{s}$, causes hydraulic shear and a considerable pressure drop, so that high disintegration of the dispersed phase into droplets of about $1 \mu \mathrm{m}$ or less can be obtained. The high pressure homogenizer is supplied by the pre-emulsion, which can be characterized by relatively large droplet diameter, which are dispersed into the smaller ones while shear and cavitation forces act on the flow in the described device. Values of these forces are regulated by the size of the gap in the homogenizing valve. Usually two-stage high-pressure emulsification is used. In the first stage, the emulsion of the pre-emulsion is ground up. The second step is to stabilize the emulsion, which consists in breaking up the disperse phase droplets formed after the first stage. Homogenizers of this type are used to create emulsions characterized by increased stability obtained due to the high grinding of the emulsion particles. Industrial pressure homogenizers usually work in the pressure ranges from 3 to $20 \mathrm{M} \mathrm{Pa}$. There is a linear relationship between the size of the applied pressure and the size of the obtained droplets diameter of the dispersed emulsion phase. Emulsification under higher pressure conditions results in greater disintegration of the dispersed phase.

\subsubsection{Ultrasound emulsification [18]}

In this type of devices, capillary interfacial waves are responsible for the emulsification processes, in addition to the cavitation. These waves propagate at the interface, without penetrating into the center. When increasing the intensity of ultrasound, the amplitude of the capillary wave increases to such a value at which the droplets of liquid break off the wave spines and are ejected into the scattering phase (fig. 2, step I). Then the initial droplet can be divided into smaller ones via the same mechanism (fig. 2, step II).The most important process parameters affecting the efficiency of ultrasonic emulsification are: power, duration of emulsification and frequency of ultrasonic waves. In ultrasonic homogenizers, emulsions with a very high disintegration of the dispersed phase can be obtained. The process of emulsion production in the ultrasonic field is very complex and depends not only on the physical conditions of ultrasound, but also on the type, physicochemical properties and acoustic parameters of immiscible liquids.

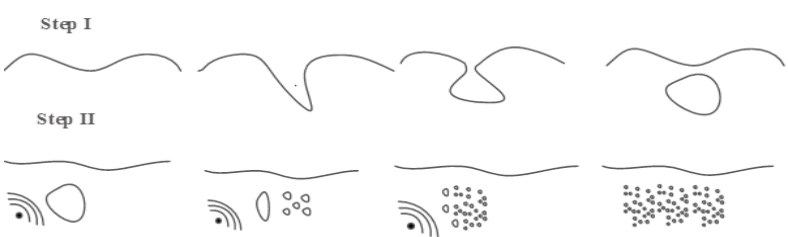

Fig. 2. Ultrasound emulsification: droplet formation and breakup.

\subsubsection{Membrane emulsification [19], [20], [21]}

In the emulsification process using membranes made of ceramic or porous glass, the dispersed phase is forced through the pores of the membrane into a second liquid which is a continuous phase (fig. 3). The continuous phase flows along the inner surface of the membrane and entrains the forming drops at the pore outlets. During the continuous phase squeezing through the tubular membranes with the same pore diameter, low pressures at about $200 \mathrm{kPa}$ are used. Diaphragm homogenizers can work in a serial or parallel system. When emulsifying with porous membranes, the emulsion drops are formed by direct dispersion and there is no effect of breaking forces of the emulsion particles to create the smaller ones - as occur in the others emulsification methods. The supplied energy is consumed to overcome the porous structure of the membranes and to detach the forming droplet phase dispersed by the flow of the continuous phase. The membranes applied in the process can by characterized by pores of a various diameters to obtain emulsions of a wide range of droplet sizes. The membranes should be made of materials resistant to cracks under the pressure applied during emulsification. The most common materials are glass or ceramic. Emulsions with a higher degree of disintegration are obtained by set of membranes application. Each set consists of several membrane layers. Polarity is also a very important feature. The membranes should not be wetted by the dispersed phase. Hydrophobic membranes are used in the preparation of w/0 emulsions, and hydrophilic in the preparation of o/w type. The particle size of the disperse phase depends on the pore size of the membrane, the emulsifier and its concentration, the type of membrane surface and the flow velocity of the continuous phase but also of the transmembrane pressure. 


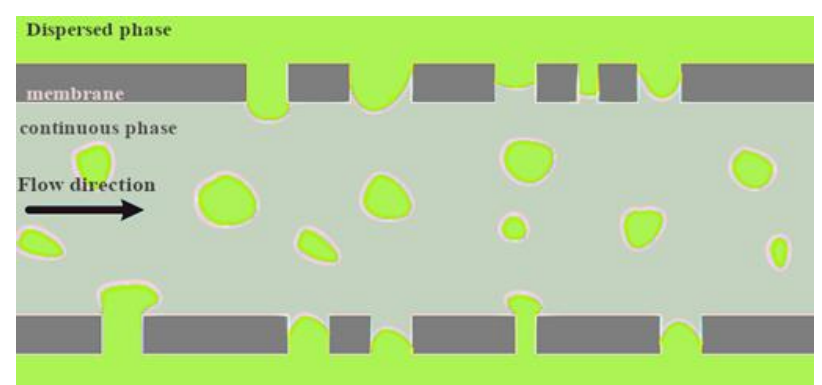

Fig. 3. M embrane emulsification.

\subsection{Emulsions stability}

As mentioned before, emulsions as a colloid systems are thermodynamically unstable [22], although their kinetic stability can be achieved. In the two immiscible liquids system minimum energy corresponds with the two layer system (only one contact surface) [23]. In emulsions droplets at the scale of microns are considered. This is relatively large scale, so due to the significant droplet area, the excess Gibbs energy is high and not easily compensable by the entropy contributions like in case of microemulsions. Surface forces working in the emulsion system were described in [24]. Due to the interfacial surface tension, the emulsion can evaluate via various mechanisms leading to its dehomogenization. Main mechanisms are presented in the fig. 4.

Creaming - is the process in which the emulsion droplets concentrate above the main emulsion fraction [25]. Finally the majority of the suspended droplets is located at the top. The creaming mechanism can be realized in different ways, depending on i.e. droplet concentration, polydispersity or inter-particle interaction.

Sedimentation - is the emulsion destabilization mechanism in which the dispersed droplets concentrate at the bottom of the vessel. Initial droplet size has an influence on the sedimentation time (the larger the droplet the faster goes down). Sedimentation occurs i.e. in the w/0 emulsions in which the density of the dispersed phase is greater than the continuous phase density [26].

Flocculation is the process basing on the droplets agglomeration with no rupture of the stabilization layer [25]. Sometimes flocculation contributes to the creaming, because of the fact that agglomerates are greater than a single particle so can move faster in the continuous phase. Flocculation can also lead to coalescence.

Coalescence is the process of droplet merging. After coal escence the dispersed phase droplets have significant greater dimensions [27], which can contribute to force other emulsion destabilization mechanisms like creaming. The coalescence mechanism is deeply described in [28].

Emulsion breaking is the process consisting in the phase separation into two layers. In some cases the coalescence and creaming can cause an inadvisable emulsion break, which means going back to the thermodynamic equilibrium. In several industries emulsion break can be desired, i.e. when the phase separation is required. For this purpose electrochemical techniques [29] or microfiltration membranes [30] can be applied.

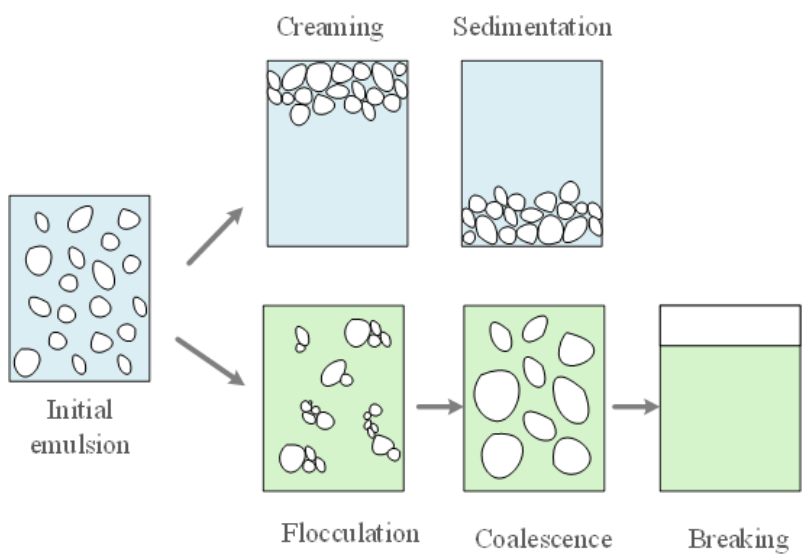

Fig. 4. Emulsion instability mechanisms.

\section{Surfactants}

Generally, surfactants are compounds that's aim is to decrease the surface tension (or interfacial tension) between two phases i.e. liquids. Surfactants are widely used to grow up the emulsion stability [31] and prevent the emulsion break. The surfactant molecule consists of two main parts: hydrophilic and hydrophobic. Surfactant particles concentrate in the region of phase boundaries, and orient in the way that the hydrophilic part is submerged in water phase while the hydrophobic - in the organic phase. Hereby the surfactant particle works as a phase connector by decreasing the surface tension. According to [32] surfactants can be classified as:

Anionic

- Sulfate Esters

- Sulfonic A cid Salts

- Carboxylate Soaps and Detergents

- Phosphoric Acid Esters and Related Surfactants

Cationic

Nonionic Surfactants

- Polyoxyethylene-B ased Surfactants

- Derivatives of Polyglycerols and Other Polyols

- Block Copolymer Nonionic Surfactants

- M iscellaneous N onionic Surfactants

Amphoteric Surfactants

- Imidazoline Derivatives

- Surface-Active B etaines and Sulfobetaines

- Phosphatides and Related Amphoteric Surfactants

The scientists have addressed the problem in the surfactant selection so the concept of the hydrophiliclipophilic balance (HLB) parameter were created. The HLB is an experimental conception to describe the hydrophilic or lipophilic properties of the surfactant particle [33]. This parameter was accepted by the wide range of researchers and industrial engineers. The HLB is determined basing on the hydrophilic and lipophilic group strength and number of each groups per particle. Surfactant application depending on the HLB value is presented in the Table 1. 
Table 1. Surfactant application for various HLB values.

\begin{tabular}{|l|l|}
\hline HLB & application \\
\hline $1.5-3$ & anti-foaming \\
\hline $3-6$ & w/o emulsions \\
\hline $7-9$ & wetting agents \\
\hline $8-12$ & o/w emulsions \\
\hline $15-20$ & solubilizer or hydrotrope \\
\hline
\end{tabular}

While introducing more than one emulsifier to the system, the HLB value can be calculated as a sum of each HLB weighted by added mass of each of them [34]

\section{Methodology}

The aim of the research was to determine the proper surfactant for the water emulsification with the light gasoline fractions addiction. As reported in [35], typical surfactant concentration vary from 1-8\%, that is why in the paper the concentration was assumed at the level of $4.6 \%$. A mixture consisting of the following ingredients was created:

- $1 \mathrm{ml}$ of heavy oil

- $3 \mathrm{ml}$ of light gasoline fraction

- $6 \mathrm{ml}$ of water

- $0.25 \mathrm{ml}$ Rokwinol 80 (stabilizer)

- $0.5 \mathrm{ml}$ of surfactant (provided by PCC Rokita, listed in the Table 2)

The organic fraction (heavy oil and gasoline) was mixed with the surfactant and stabilizer. Water was added to the thus formed mixture and stirred for $120 \mathrm{~s}$ on a magnetic stirrer (1100 rpm). The emulsion was then poured into the test tube and its properties were evaluated at selected time steps.

\section{Results}

The results are presented as a water phase fraction change at time (fig. 5). One hour period was taken into account. Conducted research aim was to select surfactant for the further experiment, in which the authors focused on the surfactant concentration optimisation. Basing on the obtained results two surfactants were chosen to be taken into account during the further research: Roksol EM B2 and Rokanol 03.

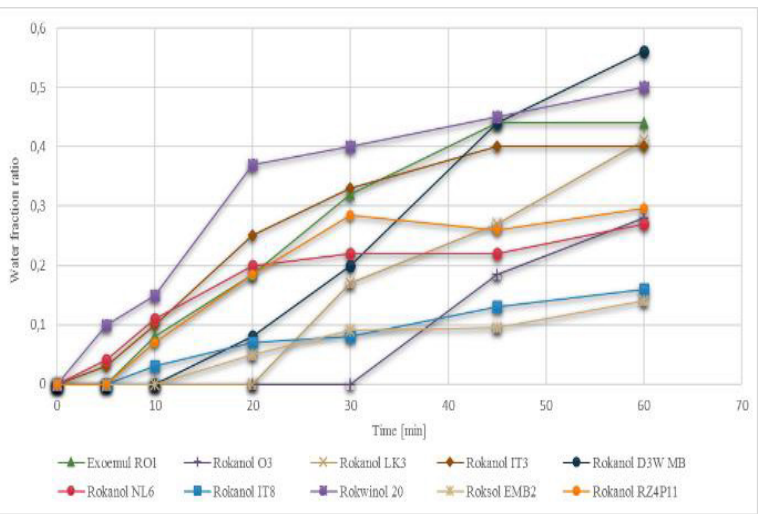

Fig. 5. W ater phase ratio as a function of time.

Table 2. Examined surfactants.

\begin{tabular}{|l|l|l|l|l|}
\hline No. & Commercial name & Composition & HLB & Solubility in water \\
\hline 1 & Rokanol RZ4P11 & Alcohols, C16-18 (even), ethoxylated, propoxylated & 3.3 & low, creates emulsions \\
\hline 2 & Exoemul RO1 & mix & 6.9 & low \\
\hline 3 & Rokanol O3 & (Z) -9-Octadecen-1-ol, ethoxylated & 7.1 & low \\
\hline 4 & Rokanol LK3 & Alcohols, C12-14, ethoxylated & 7.8 & low, creates turbid solutions \\
\hline 5 & Rokanol IT3 & C13 alcohols, branched, ethoxylated & 8 & low, creates emulsions \\
\hline 6 & Rokanol D3W MB & C10 alcohol, ethoxylated & 8.6 & low, creates emulsions \\
\hline 7 & Rokanol NL6 & Alcohols, C9-11, ethoxylated & 12.5 & good \\
\hline 8 & Rokanol IT8 & Alcohols, C13, branched, ethoxylated & 12.8 & good \\
\hline 9 & Rokwinol 80 & sorbitan monooleate, ethoxylated & 15 & good \\
\hline 10 & Rokwinol 20 & Sorbitan monolaurate, ethoxylated & 16.7 & good \\
\hline 11 & Roksol EMB2 & 2,2-iminodiethanol & no data & low, creates turbid solutions \\
\hline
\end{tabular}

\section{Concentration optimization}

To optimize the surfactant concentration the emulsions consisting of the following ingredients were prepared:

- $1 \mathrm{ml}$ of heavy oil

- $3 \mathrm{ml}$ of light gasoline fraction

- $6 \mathrm{ml}$ of water

- $\quad$ 0,1 ml Rokwinol 80 (stabilizer)

- Surfactant
The procedure was the same as described in Chapter 4. The concentration of the surfactant vary from $2-10 \%$. From the economic point of view, the lower surfactant consumption the more viable process. Comparing Roksol EMB 2 with Rokanol 03 it can be claimed that the second one is characterised by longer stability time while shifting to the lower surfactant concentration (fig. 6-7). The emulsion is stable for minutes, which seems to fulfil the requirement for the process needs. Taking into account the fact, that continuous mixing of the emulsion prevent its dissection Rokanol 03 at the 
lowers considered concentration seems to be the best solution for the thermal utilisation of the oily water purpose.

The paper authors considered also the emulsion in which the total sum of the surfactant and stabilizer equals to $1 \%$. Two mixing times were taken into account: $120 \mathrm{~s}$ and $720 \mathrm{~s}$. The obtained mixtures at the selected times are presented in the fig. 8-9. Comparing this two products, it can be noticed that increasing the mixing time can help to extend the stability time. Although the obtained product was not fully emulsified, so the surfactant concentration was too low.

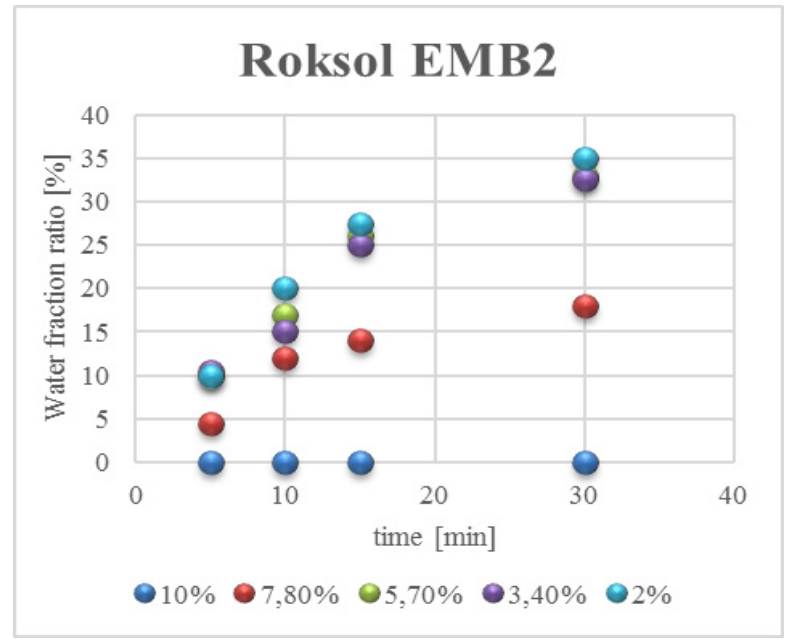

Fig. 6. Water fraction ratio change in time, various surfactant concentration, Roksol EM B2.

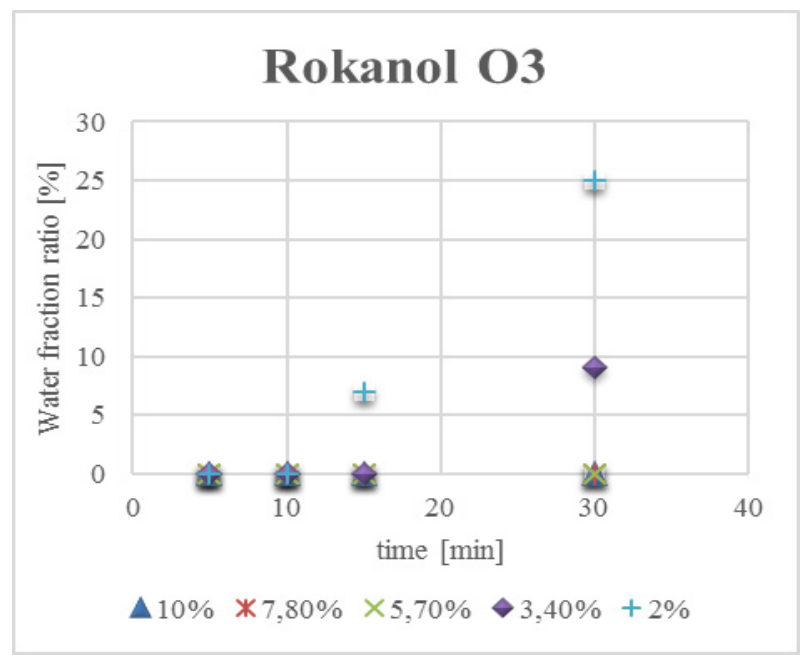

Fig. 7. Water fraction ratio change in time, various surfactant concentration, Rokanol 03.

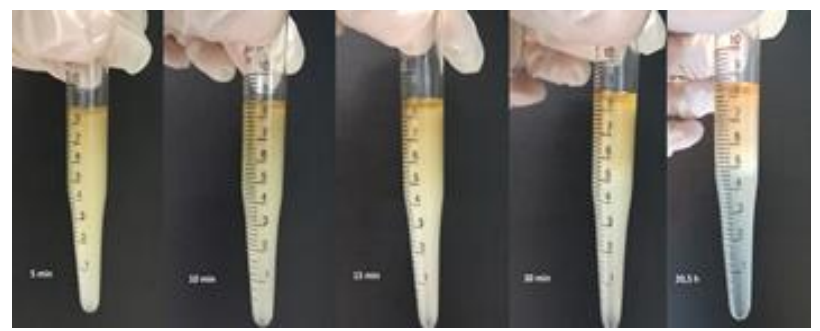

Fig. 8. Rokanol 03+Rokwinol 80, concentration $1 \%$, mixing time $120 \mathrm{~s}$.

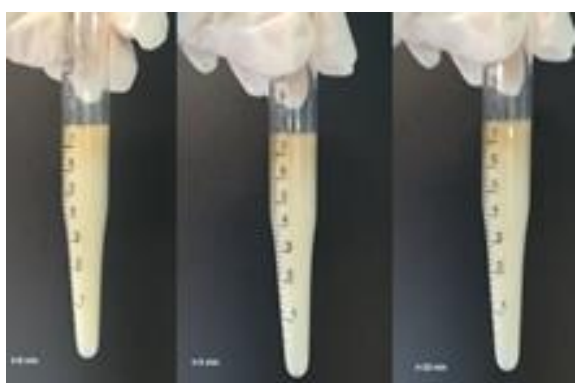

Fig. 9. Rokanol 03+Rokwinol 80, concentration $1 \%$, mixing time $720 \mathrm{~s}$

\section{Outcomes}

Oily water is the side product of wide range of industries and its disposal is still challenging. The authors proposed the way of its utilisation by emulsification with the light gasoline fraction and combustion. The aim of this paper was to examine various surfactants and optimise its concentration. The Rokanol 03 (HLB=7.1) with Rokwinol 80 ( $H L B=15)$ were selected as a best mixture of emulsifiers for the described purpose. Our results are in good agreement with the theory of the HLB factor (o/w emulsion stabilisation corresponds with HLB from 8 to 12). First emulsion combustion tests were conducted, but further research in this area is needed.

\section{References}

1. Shui $Y, Y$ an $L, B$ ao $C$, Jiang $L$. Treatment of oily wastewater by organic - inorganic composite tubular ultrafiltration ( UF ) membranes, 2006; 196: 76-83.

2. Soltani S, M owla D, V ossoughi M, Hesampour $M$. Experimental investigation of oily water treatment by membrane bioreactor. DES, 2010; 250(2): 598-600.

3. Beall GW. The use of organo-clays in water treatment, 2003; 24: 11-20.

4. Secerov Sokolovic R, Sokolovic S, Sevic S. Oily water treatment using a new steady-state fiberbed coal escer, 2009; 162: 410-5.

5. Syed S, Alhazzaa M I, A sif M. Treatment of oily water using hydrophobic nano-silica. Chem Eng J, 2011; 167(1): 99-103.

6. Cheryan M, Rajagopalan N. M embrane processing of oily streams W astewater treatment and waste reduction, 1998; 151.

7. B ande RM, Prasad B, M ishra IM, W asewar KL. Oil field effluent water treatment for safe disposal by electroflotation, 2008; 137(A ugust 2006): 503-9.

8. A hmadun F, Pendashteh A, A bdullah LC, B iak DRA, M adaeni SS, A bidin ZZ. Review of technologies for oil and gas produced water treatment. J Hazard M ater, 2009; 170: 530-51.

9. $\mathrm{YuL}, \mathrm{Han} \mathrm{M}, \mathrm{HeF}$. A review of treating oily wastewater. A rab J Chem, 2017.

10. Haeberle S, Zengerle R, Ducre J. Centrifugal generation and manipulation of droplet emulsions. M icrofluid Nanoflui, 2007: 65-75. 
11. Wong SF, Lim JS, D ol SS. Crude oil emulsion: A review on formation, classification and stability of water-in-oil emulsions. J Pet Sci Eng, 2015; 135: 498-504.

12. M atter $S, A$ dams $L L A, K$ odger TE, K im S, Shum C, W eitz DA. Single step emulsification for the generation of multi-component double, 2012: 10719-24.

13. Sauret $\mathrm{A}$, Cheung Shum $\mathrm{H}$. Forced generation of simple and double emulsions in all-aqueous systems, 2013; 154106(N ovember 2011): 1-5.

14. Schuler $F$, Paust $N$, Zengerle $R$, Stetten $F$ V on. Centrifugal Step E mulsification can Produce W ater in Oil Emulsions with Extremely High Internal V olume Fractions, 2015: 1180-8.

15. Dalmazzone $\mathrm{C}$. The M echanical Generation of E mulsions. Lubr Sci, 2005(February).

16. Floury J, Desrumaux A, Lardieres J. Effect of high-pressure homogenization on droplet size distributions and rheological properties of model oil-in-water emulsions. Innov Food Sci Emerg Technol, 2000: 127-34.

17. Schultz BS, Wagner $G, U$ rban $K$, Ulrich J . Review High-Pressure Homogenization as a Process for E mulsion Formation, 2004(4): 3618.

18. Canselier JP, Delmas H, Wilhelm AM, Abismaï B. Ultrasound Emulsification - A n O verview, 2010; 2691(2002).

19. Holdich RG, Dragosavac M M, V ladisavljevic GT, K osvintsev SR. M embrane E mul sification with $O$ scillating and Stationary M embranes. Ind Eng Chem Res, 2010: 3810-7.

20. Joscelyne SM, Trägårdh G. Membrane emulsification - a literature review. J M emb Sci, 2000; 169(October 1999): 107-17.

21. Charcosset C, Limayem I, Fessi H. The membrane emulsification process - a review, 2004; 218(M ay 2003): 209-18.

22. Florence AT, Rogers JA. Emulsion Stabilization by non-ionic surfactants: experiment and theory, 1971(1950): 233-51.

23. Goff HD. Instability and Partial Coalescence in Whippable Dairy Emulsions. J Dairy Sci, 1997; 80(10): 2620-30.

24. Sjoblom J. Emulsions and emulsion stability., 2005.

25. B oyd J, Parkinson C, Sherman P. Factors Affecting Emulsion Stability, and the HLB Concept, 1972; 41(2).

26. Rousseau D, Hodge SM. Stabilization of waterin-oil emulsions with continuous phase crystals. Colloids and Surfaces, 2005; 260: 229-37.

27. Yarranton HW, U rrutia P, Sztukowski D M . Effect of interfacial rheology on model emulsion coalescence II Emulsion coalescence, 2007; 310: 253-9.

28. Saito $\mathrm{H}, \mathrm{K}$ awagishi $\mathrm{A}, \mathrm{T}$ anaka $\mathrm{M}, \mathrm{T}$ animoto $\mathrm{T}$, Okada S. Coal escence of Lipid Emulsions in Floating and Freeze - Thawing Processes : Examination of the Coal escence Transition State Theory, 1999; 134: 129-34.
29. Canizares $P, M$ artinez $F$, L obato J, Rodrigo M A . $B$ reak-up of oil-in-water emulsions by electrochemical techniques. J Hazard M ater, 2007; 145: 233-40.

30. Hlavacek M. B reak-up of oil-in-water emulsions induced by permeation through a microfiltration membrane, 1995; 102: 1-7.

31. Han $G$, WitJS De, Chung $T$. W ater reclamation from emulsi fi ed oily wastewater via effective forward osmosis hollow fi ber membranes under the PRO mode. Water Res, 2015; 81: 54-63.

32. Attwood D, Florence AT. Surfactant systems Their Chemistry, Pharmacy and Biology., 1983.

33. Laughlin RG. HLB, from a thermodynamic perspective. J Soc Cosmet Chem, 1981; 392: 371-92.

34. Magdassi S, Frenkel M, Garti N, K asan R. Multiple Emulsions II : HLB Shift Caused by Emulsifier M igration to External Interface, 1984; 97(2): 374-9.

35. W asan DT, Nikolov AD, A imetti F. Texture and stability of emulsions and suspensions : role of oscillatory structural forces. Adv Colloid Interface Sci, 2004; 109: 187-95. 